\title{
A new species and morphometric analysis of Cladonotella (Tetrigidae: Cladonotinae)
}

\author{
Ming Kai Tan', Josef Tumbrinck², Jessica B. Baroga-Barbecho³, Sheryl A. Yap ${ }^{4,5}$
}

\begin{abstract}
1 Department of Biological Sciences, National University of Singapore, 14 Science Drive 4, Singapore 117543, Republic of Singapore.
2 Auf der Hees 1, D-41849 Wassenberg, Germany.

3 University of the Philippines Los Baños, College, Laguna, 4031 Philippines.

4 Institute of Weed Science, Entomology, and Plant Pathology, College of Agriculture and Food Science, University of the Philippines Los Baños, College, Laguna, 4031 Philippines.

5 Museum of Natural History, University of the Philippines Los Baños, College, Laguna, 4031 Philippines.

Corresponding author: Ming Kai Tan (orthoptera.mingkai@gmail.com)
\end{abstract}

Academic editor: J. Chamorro-Rengifo | Received 17 December 2018 | Accepted 21 February 2019 | Published 23 August 2019

http://zoobank.org/56A86877-147E-4516-BEDB-90F4B3C4F5FF

Citation: Tan MK, Tumbrinck J, Baroga-Barbecho JB, Yap SA (2019) A new species and morphometric analysis of Cladonotella (Tetrigidae: Cladonotinae). Journal of Orthoptera Research 28(2): 129-135. https://doi.org/10.3897/jor.28.32464

\begin{abstract}
The genus Cladonotella (Tetrigidae: Cladonotinae) consists of four species of pygmy grasshoppers from Java and New Guinea. A new species of Cladonotella is described from Siargao Island, Philippines: Cladonotella spinulosa sp. nov. This represents the first record of Cladonotella in the Philippines. To quantify differences between species of Cladonotella, we used morphological characters to construct a neighbor-joining tree, and recovered our new species as distinct from congeners. To address the lack of natural history information on Cladonotella, we described habitat and other ecological observations made in Siargao Island on our new species.
\end{abstract}

\section{Keywords}

Orthoptera, Philippines, pygmy grasshoppers, Southeast Asia, taxonomy

\section{Introduction}

Tetrigidae, commonly known as the pygmy grasshoppers, is a speciose group of orthopterans typically characterized by a pronotum that extends to cover part or all of the abdomen (Hancock 1907a, Günther 1935, Blackith 1992). The tetrigids are distributed globally and previously studied species are known to have a specialized ecology (Tan et al. 2017a). However, classification and taxonomy of many groups of this family are still problematic, despite recent major revisionary works (e.g. Tumbrinck 2014, 2018, Storozhenko 2016, Muhammad et al. 2018). This can be attributed to the lack of clear-cut diagnoses.

Tumbrinck (2014) provided a comprehensive revision of the taxonomy of the subfamily Cladonotinae in Southeast Asia and its adjacent islands, and in New Guinea and Australia. The subfamily is comprised of 75 genera globally. There are 29 genera from Southeast Asia, many of which are still poorly known. One such genus is Cladonotella Hancock, 1909, characterized as robust and wingless with a high, elevated, and swollen pronotum between the shoulders, genicular and antegenicular teeth large, and legs covered with humps and lappets. Since the genus is currently known only from the islands of Java and New Guinea (Tumbrinck 2014) (Fig. 1), we can expect species to occur on islands between and/or near these two large islands.

Recent orthopteran surveys in Siargao Island in the Philippines revealed numerous species new to science and new locality records for other orthopterans (Tan et al. 2019a), including Agraeciini katydids and Mogoplistinae, Eneopterinae and Landrevinae crickets (see Tan et al. 2018, 2019b-d, Baroga-Barbecho et al. 2019). In this paper, we describe a new species of Cladonotella from the Philippines: Cladonotella spinulosa sp. nov. This also represents the first record of Cladonotella outside Java and New Guinea. This study aims to (1) clarify the taxonomy of Cladonotella with the use of morphometrics, (2) to describe new species of Cladonotella from Siargao Island, and (3) to perform minor cladistic analysis of the genus, specifically by constructing a neighbor-joining (NJ) tree.

\section{Materials and methods}

Collection of new species and species description. - Day and night surveys involving opportunistic collections were conducted by M.K. Tan, J.B. Baroga-Barbecho, and S.A. Yap in the forest-over limestone of Siargao Island (10-100 m.a.s.l.) in Mindanao from 14 to 18 October 2018. A single female was collected and preserved in absolute analytical-grade ethanol and later pinned and dry-preserved. One hind leg was kept in absolute analytic-grade ethanol for future molecular work. The holotype was deposited in the University of the Philippines Los Baños, Museum of Natural History (UPLBMNH), Philippines.

The specimen was photographed using a Canon EOS 500D digital SLR camera with a macro photo lens MP-E $65 \mathrm{~mm} \mathrm{f} / 2.8$ USM (1-5×). Canon Macro Ring Lite MR-14EX was used for lighting and flash. Image editing (including stacking images to produce a final image with high depth of field) was accomplished using Adobe Photoshop CC 2014. Measurements of dried-pinned 


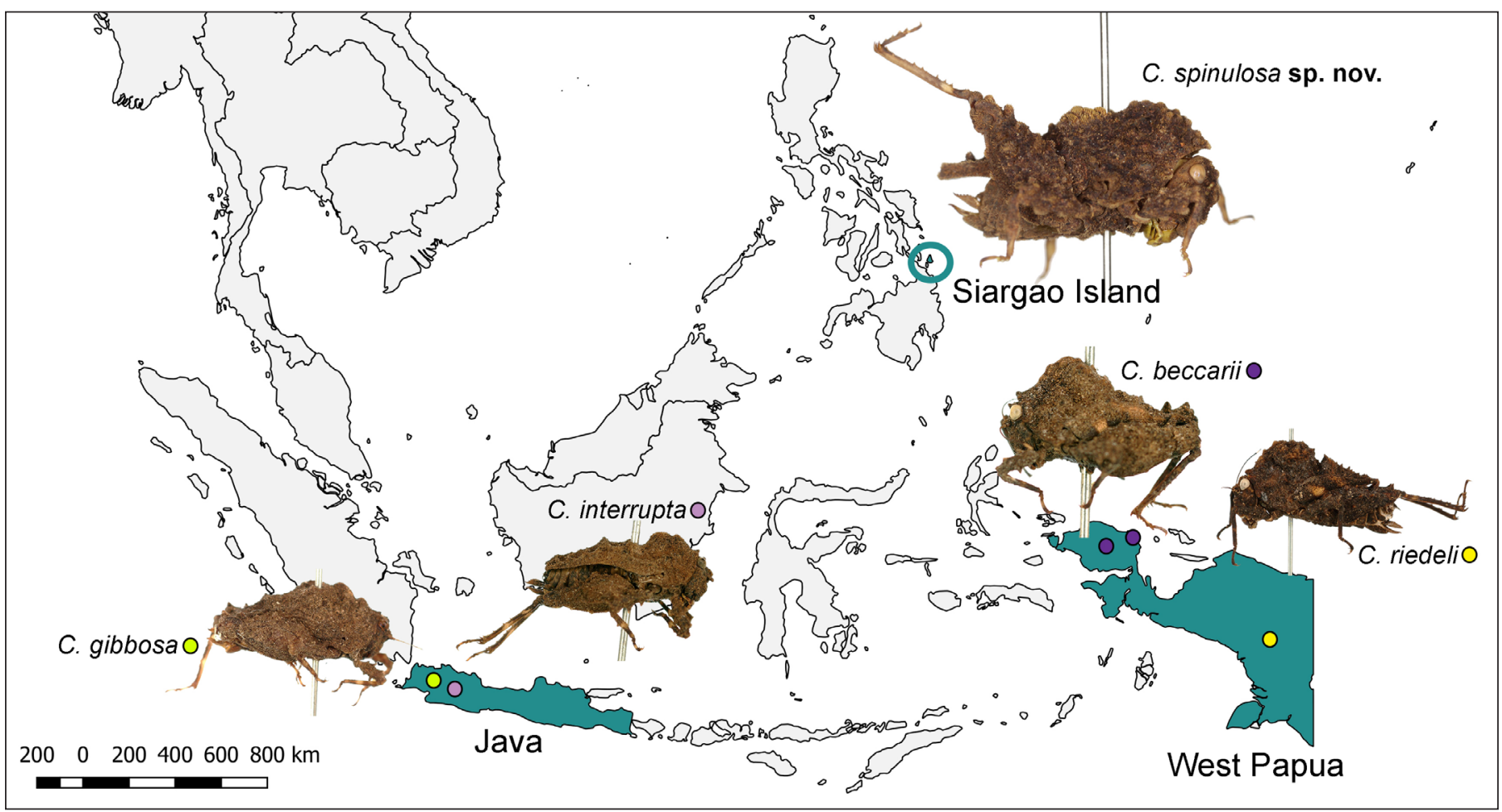

Fig. 1. Map of Southeast Asia. Colored regions indicate the current known distribution of Cladonotella. Images by J. Tumbrinck (except for Cladonotella spinulosa sp. nov.).

specimens were made using ImageJ, with calibration done using a vernier caliper. In the measurements, the following abbreviations are used (sensu Tumbrinck 2014, Tan and Artchawakom 2015):
BL body length (pronotum + head)
VW vertex width
EW eye width
SW scutellum width
posAG distance between lower margin of eyes to center of anten- nal groove
PL pronotum length
PLW pronotum lobe width
PAW width of anterior margin of pronotal disc
PPW width of posterior margin of pronotal disc
PH pronotum height (from lateral lobe)
AFL forefemur length
AFW forefemur width (maximum)
MFL mesofemur length
MFW mesofemur width (maximum)
PFL posterior femur length
PFW posterior femur width (maximum, not including lobes)
PTL posterior tibia length
bPTL posterior tarsal basal segment length
aPTL posterior tarsal apical segment length
ODL ovipositor dorsal valve length
OVL ovipositor ventral valve length

Comparative material examined.-Cladonotella beccarii (Bolívar, 1898): INDONESIA - Holotype, + , West Papua, Ramoi [northwest Doberai Peninsula, Lowland], Feb. 1875, leg. O. Beccari, Museo Civico di Storia Naturale [MSNG] "Giacomo Doria", Genova, Italy; 1 ㅇ, West Papua, Manokwari, Gunung Meja, ca. 300 m, 23-
24 Sep. 1990, leg. A. Riedel,Zoologische Staatssammlung, Munich [ZSM], Germany.

INDONESIA $\bullet 1$, holotype of Cladonotella gibbosa (Haan, 1842): Java, Gunung Pantjar, 500 m, 11-14 December 1913, leg. M. A. Lieftinck, Staatliches Museum für Tierkunde, Dresden, Germany.

Cladonotella interrupta (Bolívar, 1898): INDONESIA • Holotype, + , Giava [Java], Tcibodas, Oct. 1874, leg. O. Beccari, MSNG.

Cladonotella riedeli Tumbrinck, 2014: INDONESIA • Holotype, + , West Papua, Jayawijaya Province, Samboka, upper Kolff River, ca. 200 m, 10-14 Oct. 1996, leg. A. Riedel, ZSM.

Morphometric analysis.-To quantify morphometric and morphological differences among congeners of Cladonotella, we performed a multivariate analysis of six specimens from five species (including the new species) using seven measurements (see Tumbrinck 2014) and four categorical characters (Table 1). The six specimens (also listed in the section Comparative material examined) include all the female specimens available in the literature (see Tumbrinck 2014, Cigliano et al. 2018). Since there were fewer specimens (owing to the rarity of materials) than characters, we performed a distance-based cluster analysis and built a neighborjoining $(\mathrm{NJ})$ tree for visualization of the morphometric differences. Since the characters are categorical and continuous with interval levels, Gower distance was used to obtain a pair-wise distance matrix between different individuals using the 'daisy' function in R package 'cluster' (Maechler et al. 2012). Equal weights were provided for the data matrix. The branch length provides an indication of the distance between two particular taxa: the longer the branch length, the greater the distance. The NJ tree was constructed using the 'bionj' function in R package 'ape' (Paradis et al. 2004). To check whether the tree is a good representation of 
Table 1. Seven measurements (in $\mathrm{mm}$, data from Tumbrinck 2014) and four categorical characters used for the construction of the neighbor-joining tree. See Materials and methods for the abbreviations for measurements. The remaining abbreviations used here: $\mathrm{EP}=$ pronotum elevation in frontal view $(\mathrm{B}=$ broadened dorsad, NB = not broadened dorsad); $\mathrm{FH}=$ frontal horn of pronotum $(\mathrm{P}=$ present, $\mathrm{A}=$ absent $)$; $\mathrm{PFD}=$ posterior femur dorsal lobe $(\mathrm{R}=$ rounded, $\mathrm{A}=$ acute $) ; \mathrm{PP}=$ pronotal process $(\mathrm{H}=$ humped, $\mathrm{B}$ = banded).

\begin{tabular}{lccccccccccc}
\hline \multicolumn{1}{c}{ Taxa } & PL & PLW & PH & PFL & PFW & VW & EW & EP & FH & PFD & PP \\
\hline C. beccarii & 8.71 & 5.59 & 4.68 & 5.72 & 2.73 & 1.30 & 0.48 & NB & P & R & H \\
C. beccarii & 9.52 & 5.92 & 4.90 & 5.76 & 2.72 & 1.40 & 0.49 & NB & P & R & H \\
C. gibbosa & 9.39 & 5.44 & 3.95 & 5.60 & 2.40 & 1.15 & 0.45 & NB & P & A & B \\
C. interrupta & 7.67 & 4.68 & 2.86 & 4.81 & 1.95 & 0.90 & 0.44 & NB & A & A & B \\
C. riedeli & 10.67 & 7.12 & 6.24 & 6.64 & 2.80 & 1.54 & 0.61 & B & P & A & H \\
C. spinulosa & 10.19 & 4.87 & 3.84 & 5.29 & 2.56 & 1.72 & 0.37 & NB & P & R & H \\
sp. nov. & & & & & & & & & & & \\
\hline
\end{tabular}

the distance matrix, we obtained the correlation between original pairwise distances against pairwise distances on the tree. To evaluate the nodal support on NJ trees, 10,000 standard bootstrap replications were performed using the 'boot.phylo' function in $\mathrm{R}$ package 'ape' (Paradis et al. 2004).

\section{Results and discussion}

\section{Part I: Morphometric analysis}

The NJ tree shows that Cladonotella spinulosa sp. nov. is distinct from other congeners (with 100\% bootstrap nodal support) (Fig. 2 ). The NJ tree also recovered other species of the genus, supporting traditional taxonomy (Fig. 2). The clade separating Cladonotella riedeli Tumbrinck, 2014 of West Papua from Cladonotella gibbosa (Haan, 1842) of Java and Cladonotella interrupta (Bolívar, 1898) of Java, has nodal support $<90 \%$, probably indicating that these are the closest species. The correlation of original pairwise distances with pairwise distances on the tree had $\mathrm{a}^{2}=0.98$, indicating that the tree was a good representation of the distance matrix.

The NJ tree here is limited to only six specimens from five known species. Intra-specific variation could not be assessed here, since we only have one specimen for each species with the exception of Cladonotella beccarii (Bolívar, 1898). While our NJ tree demonstrates that the intra-specific variation of $C$. beccarii is distinctly smaller than inter-specific variations among Cladonotella species, more specimens should be included in the future. Based on our observations in Siargao Island and previous work on the genus, species of Cladonotella appear to be low in abundance in their natural habitats or, most probably, very cryptic to collectors. Currently, our NJ tree represents the only multivariate analysis for

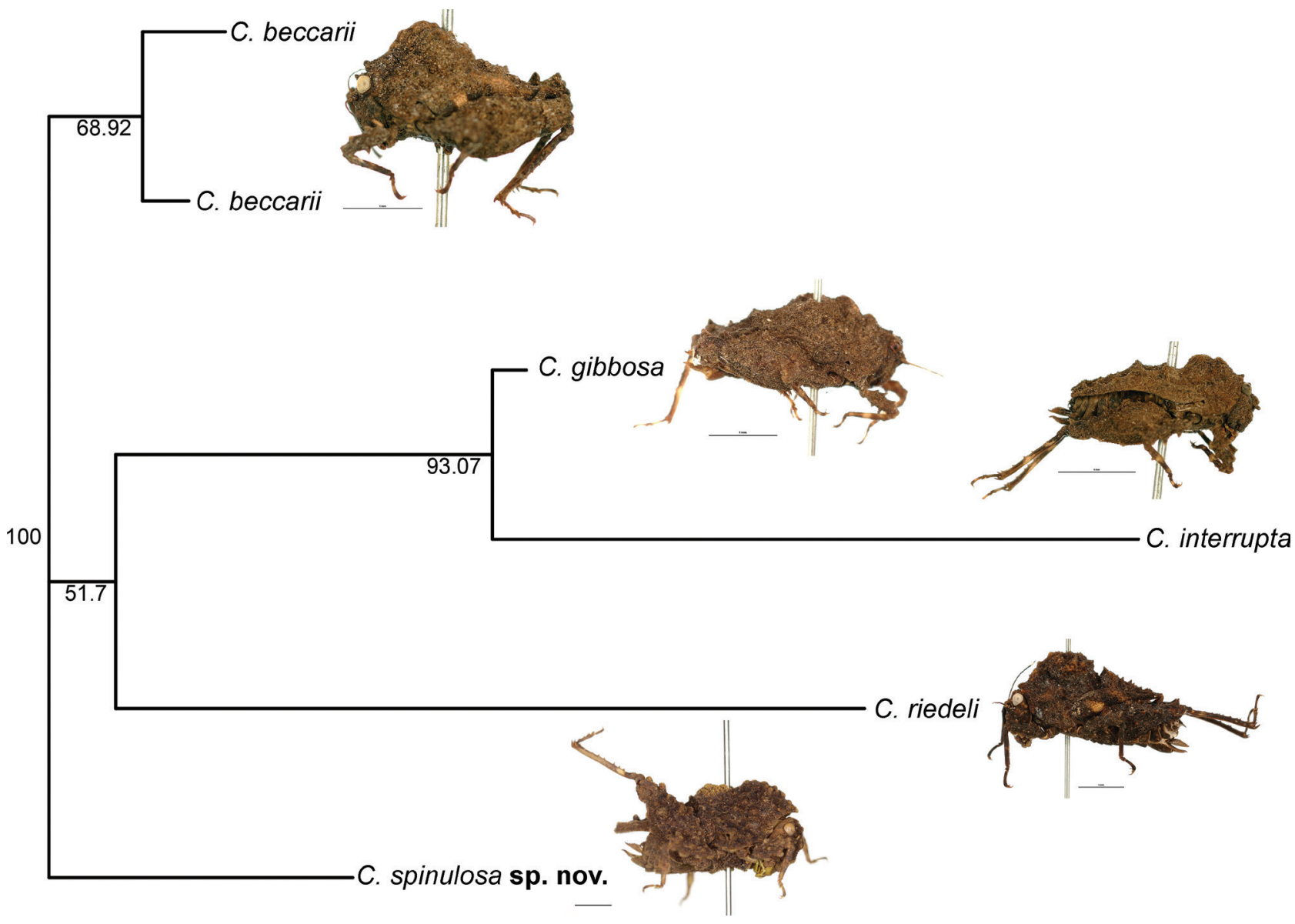

Fig. 2. A neighbor-joining tree of Cladonotella based on seven measurements (see Tumbrinck 2014) and four categorical characters. The value indicates nodal support based on 10,000 standard bootstrap replications. Images by J. Tumbrinck (except for Cladonotella spinulosa sp. nov.). 
the genus. We have measured all known specimens, yet the limited data highlight that work on the taxonomy of Cladonotella and related genera is far from complete.

Furthermore, the NJ tree does not illustrate evolutionary relationships between the taxa. We have refrained from creating a morphological phylogeny until we can be more confident of the homologous morphological characters. Alternatively, a molecular phylogeny, which has not been performed yet, can also be useful to understand the evolution of Cladonotella and other genera of Cladonotinae. However, as many species are represented with only historic museum specimens, there is a need to collect new material from Southeast Asia so that DNA can be more easily extracted and molecular data can be obtained to reconstruct phylogenetic trees.

Although we only collected one female specimen (see Part II: New species description) and we could not examine intra-specific variation, this species is very different from all congeners based on discrete morphological evidence (see Comparison with congeners section) and the NJ tree topology. As such, we are confident that the female specimen represents a novel species.

Part II: New species description

\section{Genus Cladonotella Hancock, 1909}

Type species. -Cladonotella gibbosa (Haan, 1842) [original combination: Acridium (Tetrix) gibbosum]

Remarks. - This genus comprises four species from the islands of Java and Papua (Fig. 1). It is most similar to species from Gestroana Berg, 1900 (see Tumbrinck 2014) but also shows similarities with some species of Potua Bolívar, 1887 (see Tumbrinck 2018) and Austrohancockia Günther, 1938 (see Skejo and Bertner 2017). Tumbrinck (2014) provided a comprehensive description and diagnosis of this genus, as well as comparisons with similar genera and a key to species. The detailed comparison of the Austrohancockia group of genera is also given in Skejo and Bertner (2017).

Cladonotella spinulosa Tan et al., sp. nov.

http://zoobank.org/23F03CF8-F78F-4C70-845E-B9DE54BE8DB2 Figs 3, 4

Material examined.-PHILIPPINES $\bullet 1$, holotype of C. spinulosa; Surigao del Norte, Siargao Island, Municipality of Del Carmen,

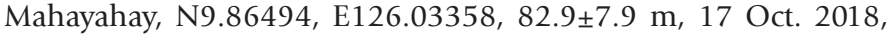
1019 hours, on rocky path, leg. M. K. Tan and J. B. Baroga-Barbecho, UPLBMNH.

Diagnosis. - The new species differs from all known species of Cladonotella by the combination of the following characters: body very nodular and lobular, with dense spinules on these nodules and lobes; vertex very wide; broader scutellum width; anterior and posterior elevations, hump-shaped (in lateral view), rugose and nodulose; anterior margin of pronotum protruding anteriorly in the middle and extending beyond anterior margin of eyes; pronotum longer and extending beyond ovipositor.

Comparison with congeners.-Apart from the unique characters of this species (in the diagnosis), the new species also differs from Cladonotella beccarii (Bolívar, 1898) of Papua by a pronotum with two elevations (instead of one), posterior end of pronotum broader but with a narrower notch in the middle, and legs more lobular and nodular; from Cladonotella gibbosa (Haan, 1842) of Java by

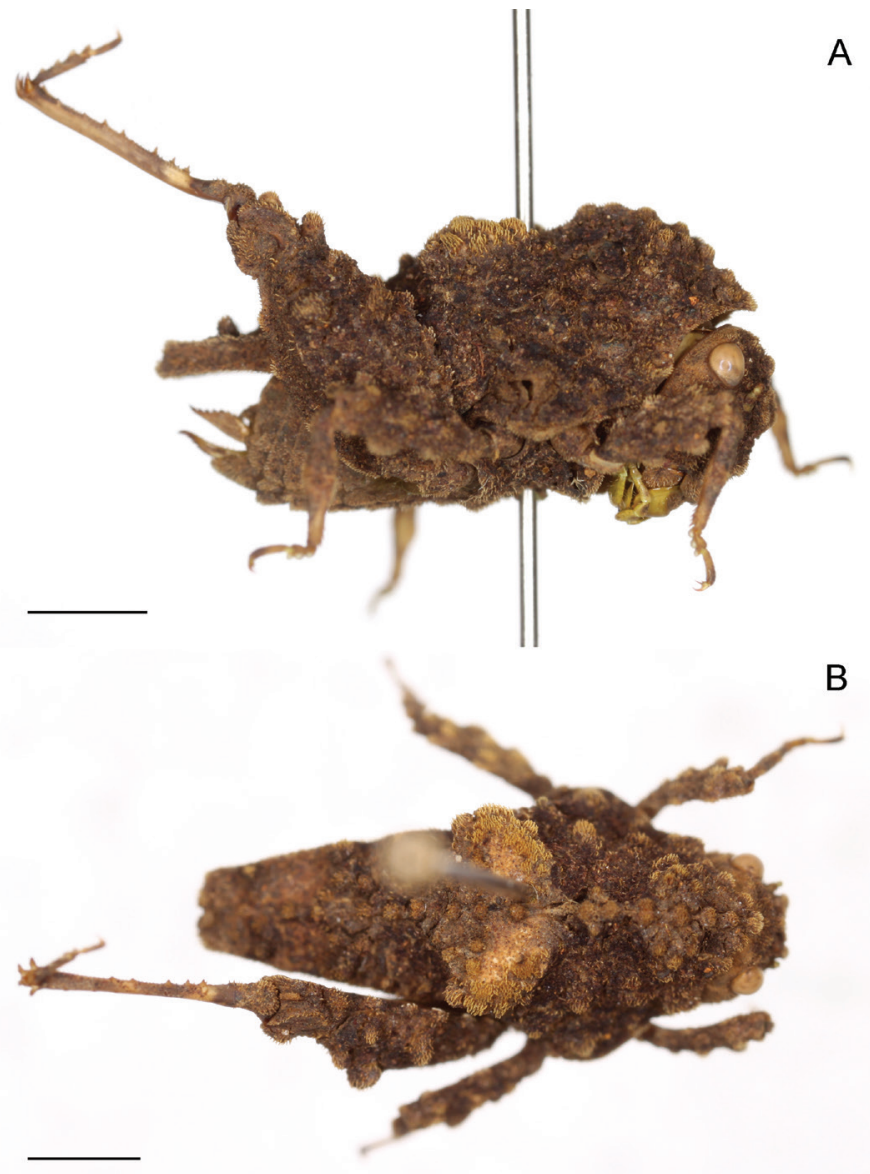

Fig. 3. Habitus of Cladonotella spinulosa sp. nov. holotype in A. Lateral and B. Dorsal views. Scale bars: $2 \mathrm{~mm}$.

two distinct and clear-cut elevations on pronotum (instead of a few irregularly shaped elevations), stouter femora; from Cladonotella interrupta (Bolívar, 1898) of Java by posterior elevation of pronotum humped-shaped (instead of acute peaks, in lateral view); from Cladonotella riedeli Tumbrinck, 2014 of West Papua by lobes and nodules on body not spine-like, sulcation between anterior and posterior elevation of pronotum less deep and truncated, lateral lobe of pronotum not acute at apex.

Holotype description. - Relatively small for the genus. Habitus as shown in Fig. 3. Brown, well camouflaged against forest floor.

Head: In frontal view: Antennal groove inserted $0.2 \mathrm{~mm}$ below lower margin of eyes (Fig. 4A). Fastigium convex in frontal view; curved on anterior border (Fig. 4A). Face very rugose and with fractures (Fig. 4A). Frontal costa stout. Bifurcation of the frontal costa in line with middle of eye (Fig. 4A). Facial carinae with spinules, curved in frontal view (Fig. 4A). Scutellum $1 \mathrm{~mm}$ wide (Fig. $4 \mathrm{~A}$ ). Compound eyes hemispheric, not exerted above vertex, pale colored, 0.5 times wider than tall. Lateral ocelli just above facial carinae and slightly above antennal groove (Fig. 4A). Margins of clypeal triangle with spinules (Fig. 4A). In dorsal view: apex of fastigium surpasses frontal margin of eyes, emarginated in the middle (Fig. 4B). Vertex very wide (Fig. 4B), 4.6 times wider than eye width. Lateral carinae of fastigium not distinct; median carina like a rounded horn (Fig. 4B). Lateral ocellus between apex of fastigium and antennal groove (Fig. 4B), located posterior of fas- 

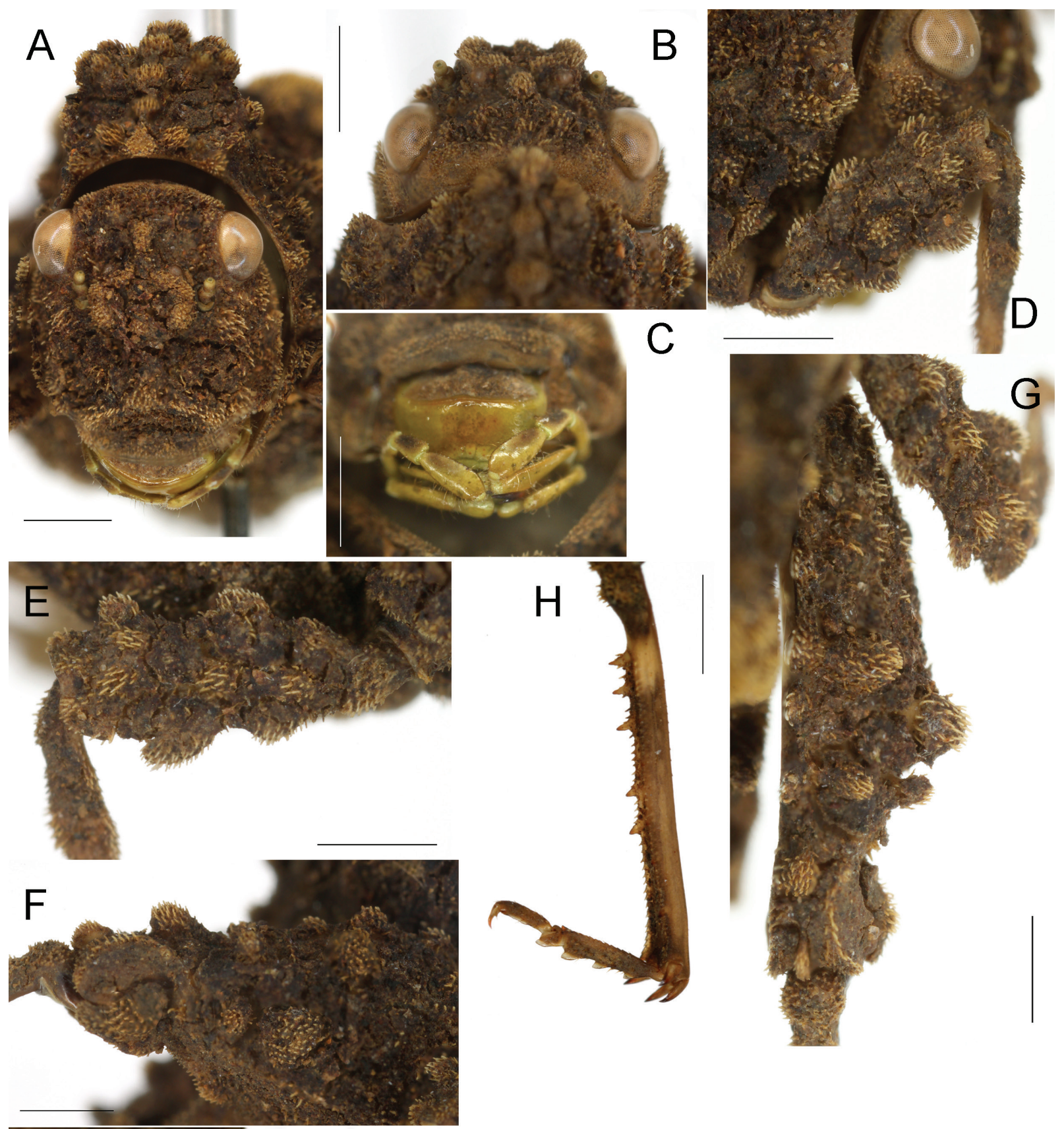

G
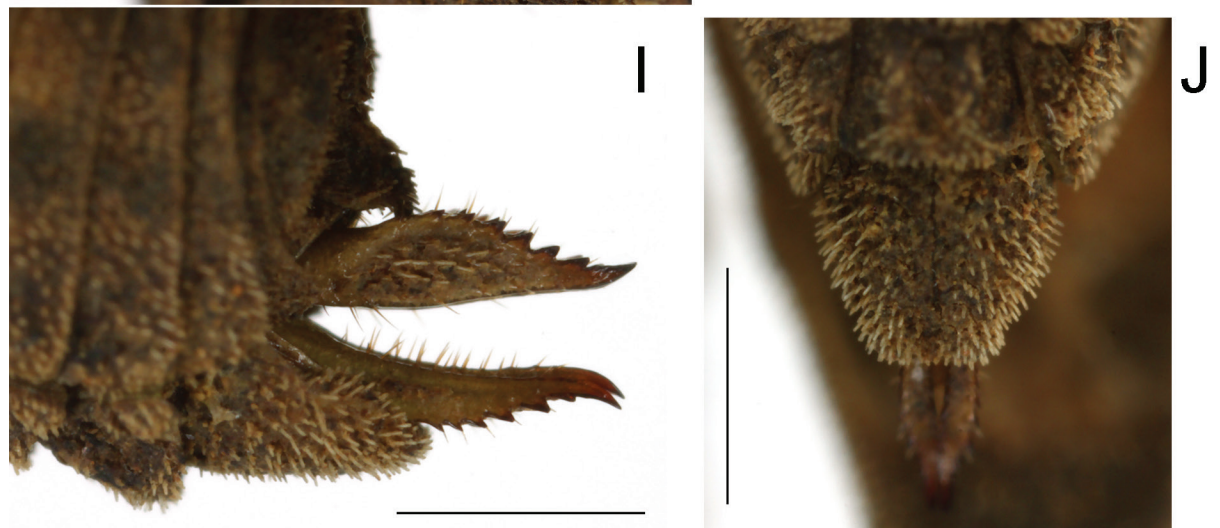

Fig. 4. Cladonotella spinulosa sp. nov. holotype: A. Face and anterior part of pronotum in frontal view; B. Head in dorsal view; C. Mouthparts in ventro-frontal view; D. Anterior and E. Middle femora in lateral views. Posterior femur in F. Lateral (posterior part) and G. Dorsal views; H. Posterior tibia and tarsus in lateral view; I. Abdominal apex in lateral view; J. Subgenital plate in ventral view. Scale bars: $1 \mathrm{~mm}$. 
cial carina. In lateral view: frontal costa arched and protruding in front of eyes. Gena with spinules. Mouthparts yellowish. Maxillary palps elongated, with apical (fifth) segment longest, following by third segment; subapical (fourth) segment shorter than both apical and third segments (Fig. 4C).

Pronotum: Pronotum, surpassing ovipositor, 2.1 times longer than wide (pronotal lateral lobe width). In lateral view: With anterior and posterior elevations, hump-shaped, rugose and nodulose (Fig. 3A); nodules covered with yellow spinules; sulcation between elevations wide but shallow (Fig. 3A). Anterior elevation $3.8 \mathrm{~mm}$ tall (measured from pronotal lateral lobe width to peak); with lateral margins straight (not tapering or broadening) dorsally in frontal view. Anterior margin of pronotal disc protruding anteriorly in the middle, surpassing anterior margin of eyes as a frontal horn (Fig. 3A). Infrascapular area broad (Fig. 3A). In dorsal view: median carina distinct throughout length of pronotum, with large nodules along the carina, nodules with yellow spinules (Fig. 3B). Second elevation of pronotal disc yellow around the peak. Lateral carinae with large nodules with yellow spinules. Interhumeral carina not distinct. Lateral lobe of pronotum with apex rounded (Fig. 3B). Apical end of pronotal disc truncated, narrowly and shallowly notched in the middle (Fig. 3B).

Legs: Coxae, trochanters, and femora with lobes and nodules, all with yellow spinules. Anterior and middle legs: anterior and middle femora stout (Fig. 4D, E). Anterior femur with three and two lobes along dorsal and ventral margins, three nodules in the external area (Fig. 4D); middle femur with three and two lobes along dorsal and ventral margins, four nodules in the external area (Fig. $4 \mathrm{E})$. Anterior and middle tibiae with stout spinules. Posterior legs: posterior femur about 2.1 times longer than wide, about 1.2 times longer than posterior tibia; with five lobes along dorsal margin, apical one large; with two nodules on dorsal of external area, anterior one larger than posterior one; one large nodule in the middle of the external area; with two lobes along ventral margin, less protruding than dorsal ones (Fig. 4F, G). Knee of posterior femur with yellow spinules along margin (Fig. 4F); both genicular tooth and antegenicular tooth rounded with yellow spinules (Fig. 4F). Posterior tibia dark near the knee, following by a pale ring (Fig. $4 \mathrm{H}$ ); with large dorsal spines, five on each lateral margin; with many yellow spinules between these dorsal large spines. Basal article of posterior tarsus 1.6 times longer than apical article; middle article very short (Fig. $4 \mathrm{H})$.

Abdomen: Tergites and sternites typically with many spinules. Epiproct with spinules. Ovipositor with yellow spinules along lateral area, especially on dorsal valve; dorsal and ventral valves with hairs along dorsal and ventral margin, denser along dorsal margin (Fig. 4I). Dorsal valve with six dorsal spines, apex acute; ventral valve with five ventral spines, apex also acute but more hooked than dorsal apex; spines on valves increasing larger and robust apically (Fig. 4I). Apices of ovipositor valves red brown (Fig. 4I). Subgenital plate with many yellow spinules, denser laterally; about as long as wide, taper slightly after basal third, apex truncated (Fig. 4J).

Measurements. $-(\mathrm{In} \mathrm{mm}) . \mathrm{BL}=10.3, \mathrm{VW}=1.7, \mathrm{EW}=0.4, \mathrm{SW}=1.0$, posAG $=0.2, \mathrm{PL}=10.2, \mathrm{PLW}=4.9, \mathrm{PAW}=1.8, \mathrm{PPW}=1.4, \mathrm{PH}=$ $3.8, \mathrm{AFL}=2.1, \mathrm{AFW}=0.9, \mathrm{MFL}=2.5, \mathrm{MFW}=1.0, \mathrm{PFL}=5.3, \mathrm{PFW}$ = 2.6, $\mathrm{PTL}=4.4, \mathrm{bHTL}=0.9, \mathrm{aHTL}=0.6, \mathrm{ODL}=1.5, \mathrm{OVL}=1.4$.

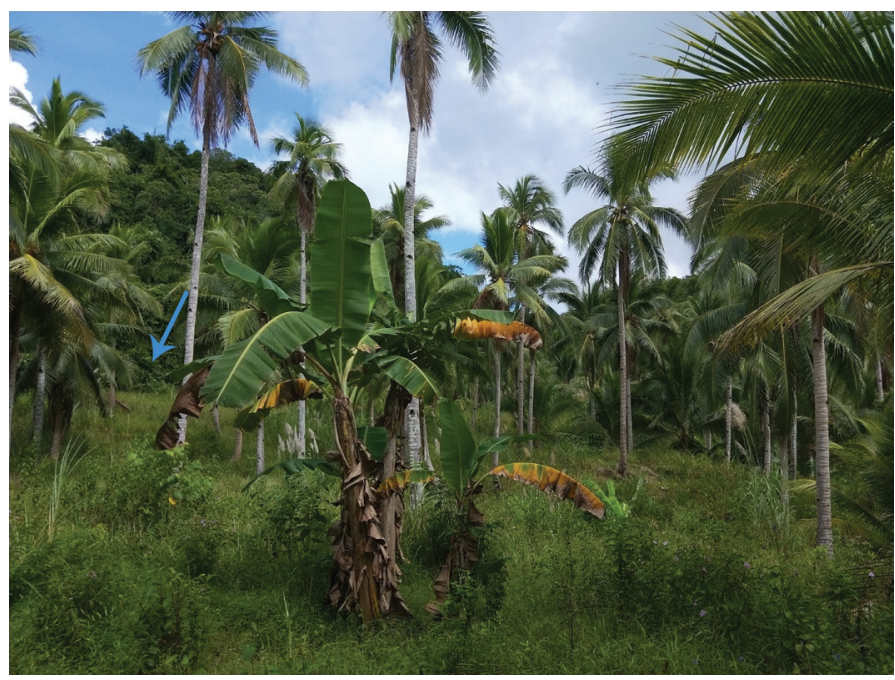

Fig. 5. Over-limestone forest in Siargao Island, the habitat of Cladonotella spinulosa sp. nov. The blue arrow indicates the location where the specimen was collected.

Habitats. - The holotype was found on a rocky path within hilly areas of over-limestone forest not too far from the coast (Fig. 5). The rocks on the path were probably limestone and were covered with wet leaf litter and dead branches. Limestone on the surface was also covered with wet mosses. This suggests that the pygmy grasshoppers probably prefer wet microhabitats, as is the case for other Southeast Asian tetrigids (Tan et al. 2017a). The forest on the hill (background of Fig. 5) is bordered by banana and coconut trees.

Etymology.-This species name refers to the many spinules all around the body and is Latin female gender adjective in nominative.

\section{Acknowledgements}

The authors would like to thank the Siargao Islands Wildlife Conservation Foundation, Inc., Mr. Jose Macavinta, Ms. Deny Comon, Mr. Jesus Comon, MODECERA project, Mayor Alfredo Coro, Jr., and the municipality of Del Carmen for the accommodation and for allowing us to conduct research in their area. The work in the Philippines was also granted by the Orthoptera Species File Grant 2018 under the taxonomic research project with the title "Advancing biodiversity informatics of Orthoptera from the Philippines". The work of MKT was also supported by the Lady Yuen Peng McNeice Graduate Fellowship of the National University of Singapore. MKT, JBB, and SAY surveyed Siargao Island, JT helped with taxonomy work, MKT analyzed the data, and all authors contributed to the writing. The authors declare that there is no conflict of interest.

\section{References}

Baroga-Barbecho JB, Yap SA,Tan MK, Robillard T (2019) Taxonomic review of the genus Paranisitra Chopard (Orthoptera: Gryllidae: Eneopterinae: Nisitrini) with description of a new species from Mindanao. Zootaxa 4568: 81-96. https://doi.org/10.11646/zootaxa.4568.1.5

Blackith RE (1992) The Tetrigidae (Insecta; Orthoptera) of South-East Asia; an Annotated Catalogue with Partial Translated Keys and Bibliography. Japaga Press, Dublin, 249 pp. 
Cigliano MM, Braun H, Eades DC, Otte D (2018) Orthoptera species file online. Version 5 (5.0). http://orthoptera.speciesfile.org/HomePage/ Orthoptera/HomePage.aspx [accessed 22 November 2018]

Günther K (1935) Acrydiinen (Orth. Acrididae) aus dem mittleren Ostrorneo gesammelt von H. C. Siebers 1925. Arbeitenüber Morphologische und Taxonomische Entomologie aus Berlin-Dahlem, 2, 257-263. [7 figs.]

Hancock JL (1907a) Orthoptera Fam. Acridiidae. Subfam. Tetriginae. Genera Insectorum, 48, 1-79. [4 pls.]

Maechler M, Rousseeuw P, Struyf A, Hubert M, Hornik K (2012) Cluster: Custer analysis basics and extensions. R package version 1: 56 .

Muhammad AA, Tan MK, Abdullah NA, Azirun MA, Bhaskar D, Skejo J (2018) An annotated catalogue of the pygmy grasshoppers of the tribe Scelimenini Bolívar, 1887 (Orthoptera: Tetrigidae) with two new Scelimena species from the Malay Peninsula and Sumatra. Zootaxa 4485: 1-70. https://doi.org/10.11646/zootaxa.4485.1.1

Paradis E, Claude J, Strimmer K (2004) APE: Analyses of phylogenetics and evolution in R language. Bioinformatics 20: 289-290. https:// doi.org/10.1093/bioinformatics/btg412

Skejo J, Bertner P (2017) No more dust and exoskeletons-In: vivo photographic records provide new data on Eufalconius pendleburyi Günther, 1938 (Orthoptera: Tetrigidae) from the Titiwangsa Mts. Annales Zoologici 67: 665-672. https://doi.org/10.3161/00034541ANZ2017.67.4.003

Storozhenko SY (2016) Review of the pygmy grasshoppers of the tribe Cleostratini (Orthoptera: Tetrigidae). Far Eastern Entomologist 326: 1-44.

Tan MK, Artchawakom T (2015) A new species from the genus Gorochovitettix (Tetrigidae: Metrodorinae) from Thailand. Zootaxa 3990: 444-450. https://doi.org/10.11646/zootaxa.3990.3.9

Tan MK, Baroga-Barbecho JB, Yap SA (2019d) Taxonomic notes on Trigonidium and related groups with one new species from the Philippines (Orthoptera: Trigonidiidae; Trigonidiinae). Zootaxa 4564: 573-587. https://doi.org/10.11646/zootaxa.4564.2.13
Tan MK, Baroga-Barbecho JB, Yap SA (2019a) An account on the Orthoptera from Siargao Island (Southeast Asia: Philippines: Mindanao). Zootaxa 4609: 1-30. https://doi.org/10.11646/zootaxa.4609.1.1

Tan MK, Gorochov AV, Baroga-Barbecho JB, Yap SA (2019b) A new species of Landrevinae (Orthoptera) from the Philippines, with notes on Endodrelanva and Endolandrevus (Orthoptera: Gryllidae; Gryllinae; Landrevini). Zootaxa 4544: 285-295. http://doi.org/10.11646/ zootaxa.4544.2.8

Tan MK, Ingrisch S, Baroga-Barbecho JB, Yap SA (2019c) New species of Ornebius (Orthoptera; Mogoplistidae; Mogoplistinae) from Siargao Island of the Philippines. Zootaxa 4590: 166-176. https://doi. org/10.11646/zootaxa.4590.1.7

Tan MK, Ingrisch S, Robillard T, Baroga-Barbecho JB, Yap SA (2018) New taxa and notes on spine-headed katydids (Orthoptera: Conocephalinae: Agraeciini) from the Philippines. Zootaxa 4462: 331-348. https://doi.org/10.11646/zootaxa.4462.3.2

Tan MK, Yeo H, Hwang WS (2017a) Ground dwelling pygmy grasshoppers (Orthoptera: Tetrigidae) in Southeast Asia tropical freshwater swamp forest prefer wet microhabitats. Journal of Orthoptera Research 26: 73-80. https://doi.org/10.3897/jor.26.14551

Tumbrinck J (2014) Taxonomic revision of the Cladonotinae (Orthoptera: Tetrigidae) from the islands of South-East Asia and from Australia, with general remarks to the classification and morphology of the Tetrigidae and descriptions of new genera and species from New Guinea and New Caledonia. In: Telnov D (Eds) Biodiversity, Biogeography and Nature Conservation in Wallacea and New Guinea, II: 350-396.

Tumbrinck J (2018) A new species of Thoradonta from New Guinea with some remarks on other Tetrigidae (Orthoptera) taxa from Indo-Australia. Suara Serangga Papua (SUGAPA digital) 11: 27-46. https://doi. org/10.19269/sugapa2018.11(1).05 